\title{
SEISMIC DAMAGE SCENARIOS IN KALAMATA (S. GREECE)
}

\section{Kazantzidou-Firtinidou D. ${ }^{1}$, Kassaras I. ${ }^{2}$, Ganas A. ${ }^{1}$, Tsimi C.. ${ }^{1}$, Sakellariou N. ${ }^{2}$, Mourloukos S. ${ }^{2}$, Stoumpos P. ${ }^{2}$, Michalaki K. ${ }^{2}$ and Giannaraki G. ${ }^{2}$}

${ }^{I}$ National Observatory of Athens, Institute of Geodynamics, Thisseio, Athens, Greece, danai.kazantzidou@gmail.com,aganas@gein.noa.gr

${ }^{2}$ Laboratory of Seismology, Faculty of Geology and Geoenvironment, University of Athens, Panepistimiopolis, 15784, Zografou, Athens, Greece, kassaras@geol.uoa.gr

\begin{abstract}
Damage scenarios are necessary tools for stakeholders, in order to prepare protection strategies and a total emergency post-earthquake plan. To this aim, four seismic hazard models were developed for the city of Kalamata, according to stochastic simulation of the ground motion, using site amplification functions derived from ambient noise HVSR measurements. The structural vulnerability of the city was assessed following an empirical macroseismic model, developed for the European urban environment (EMS-98). The impact of the vulnerability due to the seismic hazard potential is also investigated by means of synthetic response spectral ratios at 108 sites of the city. The expected damage grade per building block, is calculated by combining vulnerability with the respective seismic intensities, derived for the four seismic sources. The importance of the followed methodology for implementing microzonation studies is emphasized, since the expected influence of the ground motion amplification due to local soil conditions has been approximated in detail. Moreover, new fragility curves for the main structural types in Kalamata are proposed for each seismic scenario.

Keywords: Macroseismic vulnerability, microtremors, seismic risk models, damage grades, Deterministic Seismic Hazard Assessment.

\section{Пєрíi $\eta \psi \eta$}

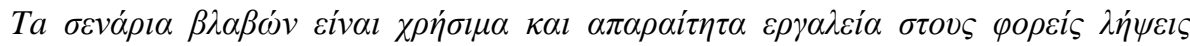

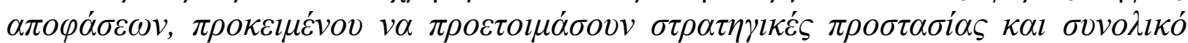

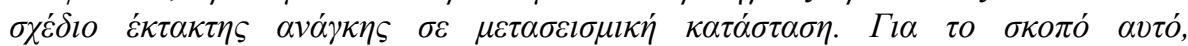

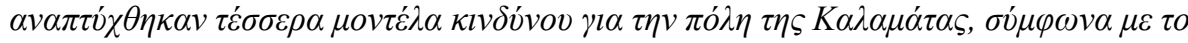

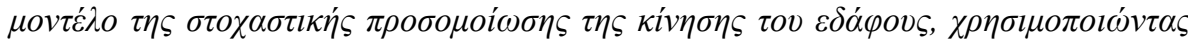

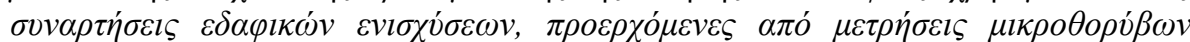

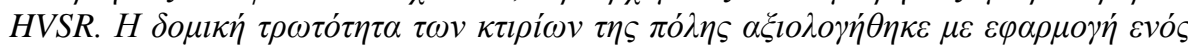

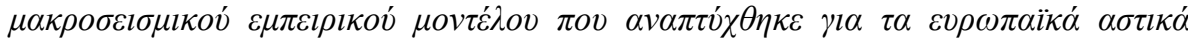

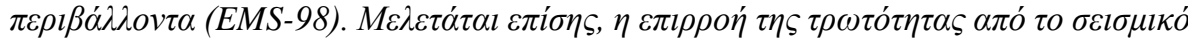

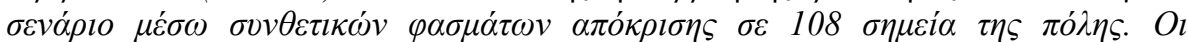

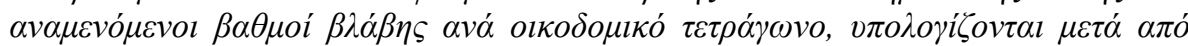

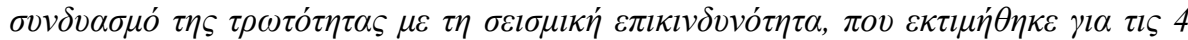

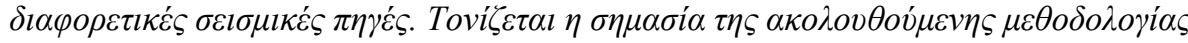

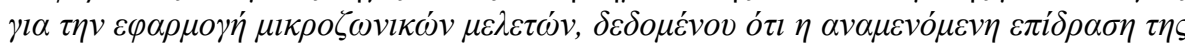




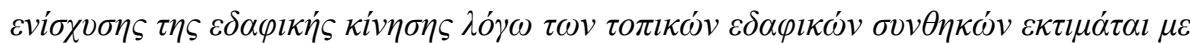

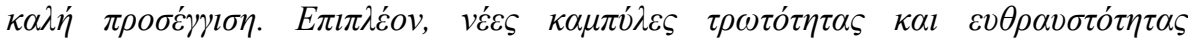

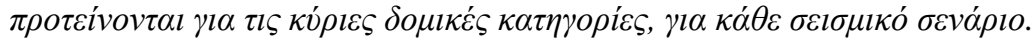

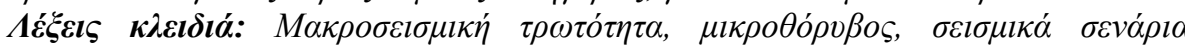

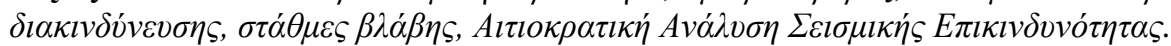

\section{Introduction}

Damage assessment allocation and loss estimations are necessary tools to stakeholders in order to prioritize geographical and sectoral interventions and to prepare a total emergency plan in postearthquake situation as well as pre-earthquake pre-eventive interventions, especially in earthquake prone densely populated zones. In this regard, the accurate as possible seismic hazard and vulnerability assessment are, along with their socioeconomic consequences "sine qua non". Nonetheless, numerous cases of strong earthquakes (e.g. Christchurch 2011, Cephalonia 2014, Nepal 2015) have manifested that the generic provisions provided by the effective national seismic codes are grossly misleading, with strong ground motion parameters and coseismic effects found far higher than predicted (Wyss and Rosset, 2013). Therefore, small scale seismic risk models are highly requested, incorporating the accurate impact of strong ground motion on the constructions of interest.

Last few decades have witnessed a growing interest worldwide towards the development of risk scenarios, that are established after the combination of the vulnerability module of the exposed sample, with the hazard module, for particular earthquake scenarios. Seismic risk models can be principally important for emergency response planning but also they can be of use for risk mitigation through calibration of existing seismic regulations (Calvi et al., 2006). Greek urban areas, although many of them being densely populated, and most importantly facing high seismic hazard, have rarely been objects of such studies and even more rarely their results have been used for extensive pre- and post-earthquake planning and interventions. The current study, aims towards the development of realistic seismic risk scenarios for the city of Kalamata (S. Greece).

The city of Kalamata is located $\sim 50 \mathrm{~km}$ away from the southwestern Hellenic Arc and hence, the area is prone to intense seismic activity caused by the convergence between the Aegean-African plates. Strong earthquakes are reported in the historical (Papazachos and Papazachou, 2003) and instrumental (Makropoulos et al., 2012) catalogues. The most recent devastating earthquake took place on September $13^{\text {th }} 1986$, with Mw5.8, that caused several casualties and heavy damage to a large part of its building stock (OASP, 1987). Due to this catastrophic event, the largest part of the city was rebuilt following the provisions of a more rigorous code issued in 1985 , hence the vulnerability of the city has been certainly enhanced. In this regard, the work herein is twofold: a) comparing the pre- and post- 1986 buildings behavior under the 1986 crisis and b) producing an extreme damage scenario evaluated by the arrangements of the former.

\section{Applied Methodologies}

\subsection{Vulnerability Assessment}

Seismic vulnerability is defined as the tendency of a structure to experience damage under a certain level of ground shaking. Vulnerability assessment is typically based on post-seismic damage observations (empirical vulnerability) and in a lesser degree on analytical studies of the exposed structures (Lagomarsino and Giovinazzi, 2006). In the current study, the vulnerability was assessed using an empirical Damage Probability Matrix approach (DPM), derived by EMS-98 macroseismic scale (Grünthal, 1998), as adapted and proposed by the RISK-UE team under the label "LM1" (Milutinovic and Trendafiloski, 2003).

According to LM1, buildings characterized by a similar seismic behaviour are grouped together into certain vulnerability classes, following a probabilistic approach. In order to quantify the building stock classification, vulnerability indexes, within probability ranges, ranging between 0 and 1 have 
been introduced. Modification scores are applied to them so as to account for specificities of each building, as suggested by Giovinazzi and Lagomarsino (2004). This method is suitable for vulnerability, damage and loss assessments in urban environments with adequate estimates on seismic intensity, and portfolios large enough so that any uncertainties associated with standardized indexes can be balanced out.

The LM1 method defines semi-empirical vulnerability functions that correlate the seismic intensity I and the vulnerability index $V_{I}$ with the mean damage grade $\mu_{\mathrm{D}}$ (Equation 1). Damage scenarios are, then, composed in terms of discrete damage probability distribution of the latter, for which the beta distribution is applied for all damage grades. Final damage grade is defined as the one that corresponds to the highest probability of occurrence.

Equation 1 - Formula of mean damage grade relating vulnerability index with seismic intensity.

$$
\mu_{D}=2.5\left[1+\tanh \left(I+6.25 V_{I}-13.1\right) / 2.3\right]
$$

The damage grade is a discrete variable characterized by 5 grades, plus the zero grade, defined as follows: D0-No damage-"green", D1-Slight damages-"green", D2-Moderate damages-"yellow", D3-Substantial to heavy damages-"yellow", D4-Very heavy damages-"red", D5-Destruction-"red". Damage scenarios are composed in terms of damage grades per block.

\subsection{Seismic Hazard assessment}

In this work Seismic Hazard is approached in a deterministic way, as suggested by Kassaras et al. (2015), aiming to resolve the nearest Maximum Credible Earthquake (MCE) motion at the municipality of Kalamata. The Deterministic Seismic Hazard Assessment (DSHA) is based on the constraints of the active tectonics in a region and the parameters that affect the seismic motion, i.e. the seismic source, the energy diminution and site effects. Seismic source is modeled by its focal mechanism and/or ideally, from the slip distribution across the fault plane. Diminution of seismic waves with epicentral distance is satisfactorily addressed by elastic-inelastic broad-scale relations derived experimentally with the use of a large amount of seismic records. Local conditions (site effects), that essentially impact the seismic wavefield, considerably vary from place to place. Hence small scale models are required for their optimal estimation and this matter is addressed herein.

Site effects were assessed by applying the Horizontal to Vertical Spectral Ratio (HVSR or H/V) (Nakamura, 1989) making use of ambient noise recordings. The theory behind the method is based on the assumption that the $\mathrm{H} / \mathrm{V}$ ratio corresponds to the transfer function of the soil column between the seismic basement and the surface. This technique is popular, as it is quite simple, swift, and economic. It is widely used in microzonation studies, providing accurate characterization models. In Greece, the HVSR technique has been frequently used, providing consistent results (Panou et al., 2005; Kassaras et al., 2014, among others).

To calculate site specific synthetic acceleration time series and the respective response spectra in Kalamata, the stochastic simulation approach was used. Stochastic simulation is useful, especially in regions where active tectonic features are well defined. It is particularly useful for simulating ground motions of most interest to engineers and is widely used to predict them for regions where recordings of strong earthquakes are not available. We used a stochastic finite-fault model, as proposed by Beresnev and Atkinson (1997), to simulate the near-source strong ground motion in the region of Kalamata. The method has been successfully implemented for the broader Aegean region by various researchers (Margaris and Boore, 1998; Roumelioti et al., 2004; Kassaras et al., 2015, among others). 


\section{Data and data analysis}

\subsection{Building stock and vulnerability}

The current study used the deliverables of the research action (EPANTYK, 2009). The data concerns the information obtained during the Census of 2001 (Source: EL.STAT.), which includes critical information regarding buildings height, use, material, construction period. In addition, vector digital maps with contours of city blocks, buildings and road axes have been provided, permitting the creation of a digital database in GIS environment (ArcGIS, QGIS). Although the obtained spatial information regards a block scale level, vulnerability per building has been assessed, by attributing RISK-UE (EMS-98) methodology. The main structural typologies found in Kalamata are masonry (stone, clay/cement bricks) and reinforced concrete frames.

Our database includes structural characterization for 7957 buildings. Their vast majority is of residential and commercial use and concerns RC frame buildings, constructed with moderate or high seismic provisions. The largest construction activity was concentrated in 1960-1970 when migration of citizens to the cities was high. Thereafter, Kalamata was reconstructed after the large earthquake of 1986 , due to which $70 \%$ of the city's buildings suffered from moderate to very heavy damage. Therefore, the vulnerability of the new buildings is expected to be significantly enhanced given that they were built according to the 1985 additional provisions to the seismic code.

\subsection{Ambient noise site characterization}

On July 2015, our research group from the University of Athens (UoA) and the Institute of Geodynamics (GI-NOA) conducted a field survey in Kalamata with the purpose of collecting microtremor data. Ambient noise was recorded at 28 selected positions. A dataset of 80 microtremors recordings (Theodulidis et al., 2004) was also considered and hence site effects were investigated for 108 positions in Kalamata.

The ambient noise time series were corrected for baseline mean and trend and were tapered with a $5 \%$ cosine function at both ends. Instrumental response correction was performed by considering the poles and zeroes configurations suggested by the manufacturer of the sensors and sensitivity values per component according to each instrument's calibration sheet. HVSR curves were computed using the GEOPSY software (SESAME, 2005). Analysis was performed in the frequency range of engineering interest $0.5-20 \mathrm{~Hz}$. The Fast Fourier Transform (FFT) was calculated for each component of the data and the spectra were smoothed using a logarithmic window. The procedure was applied to variant length windows of stationary signal after removing transients through STA/LTA anti-triggering. At each site the final HVSR curve results from the logarithmic averaging of HVSR curves for each temporal window and its standard deviation. In the current study the spectral ratios (HVSR) of microtremor measurements were validated by available geological or geotechnical data (OASP, 1996).

\subsection{Stochastic simulation of strong ground motion}

The EXSIM algorithm (Boore, 2003) was used to simulate the near-source strong ground motion in Kalamata. The rectangular fault plane was divided into small subfaults, where each subfault is considered to be a point source, which is characterized by an $\omega^{2}$ spectrum (Brune, 1970). The rupture starts at a given or a randomly set source and propagates across the whole surface of the fault. The shear wave acceleration spectrum of each subfault is expressed in terms of the source, path and site effects. Strong ground motion in Kalamata was simulated for four earthquakes scenarios: A) the Mw5.8 earthquake occurred on 13/9/1986 on Verga normal fault, B) a potential Mw6.2 earthquake on Verga fault, considered the nearest Maximum Credible Earthquake (MCE) for the Kalamata region, C) a potential Mw6.6 event on Kourtissa normal fault and D) a future Mw6.0 on Pidima normal fault (Figure 1). 
The geometry of the fault and the rupture parameters used in the simulation procedure were considered after Lyon-Caen et al. (1988) and Wells and Coppersmith (1994). Acceleration time histories and the respective response spectra were produced for 108 positions in Kalamata municipality using the deduced ambient noise HVSR curves as the sites' amplification functions. Panels A in Figure 2 present the comparison between the spectral acceleration recordings of the 1986 earthquake at the permanent stations kala and kall and the simulated ground motion at two neighboring sites, showing a good agreement for the spectral acceleration and the frequency content. The next step of the analysis was the calculation of ratios between the simulated synthetic spectral acceleration and the spectral acceleration estimated for bedrock conditions, which represent the ground motion amplification due to the soil conditions. For each scenario, the amplification ratio corresponding to the existing buildings theoretical fundamental period was extracted and it was following applied as a vulnerability index modification score (Figure 3).

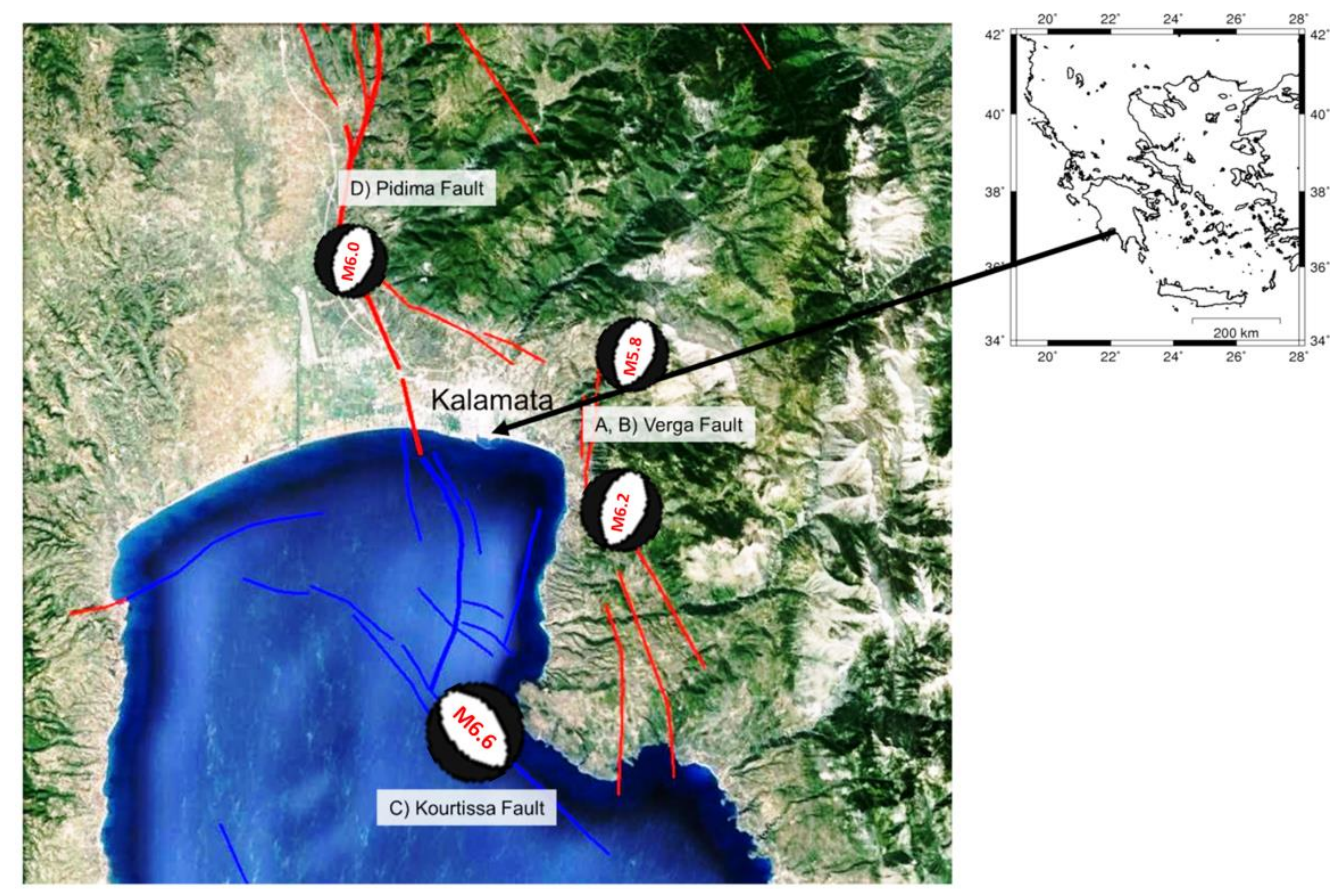

Figure 2 - Localisation of active faults for which strong ground motion was simulated (ASPIDA, 2015). The minimap on top right shows the position of Kalamata within the Greek territory.

\section{Seismic risk scenarios}

The synthetics calculated at 108 positions were combined using a natural neighborhood interpolation scheme to construct hazard maps presenting the distribution of the maximum absolute acceleration (PGA) and the seismic intensity (I), derived by the application of the empirical relation of Tselentis and Danciu (2008). Macroseismic intensities (MMI) observed during the earthquake of 1986 (Leventakis et al., 1992) are consistent with the synthetic intensities for the same event (scenario A, Figure 4 Left). 

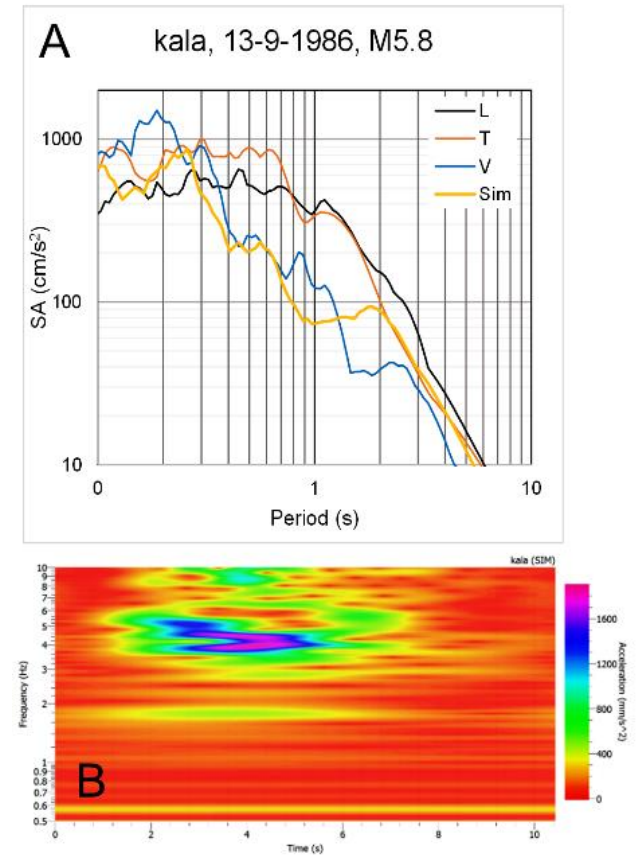
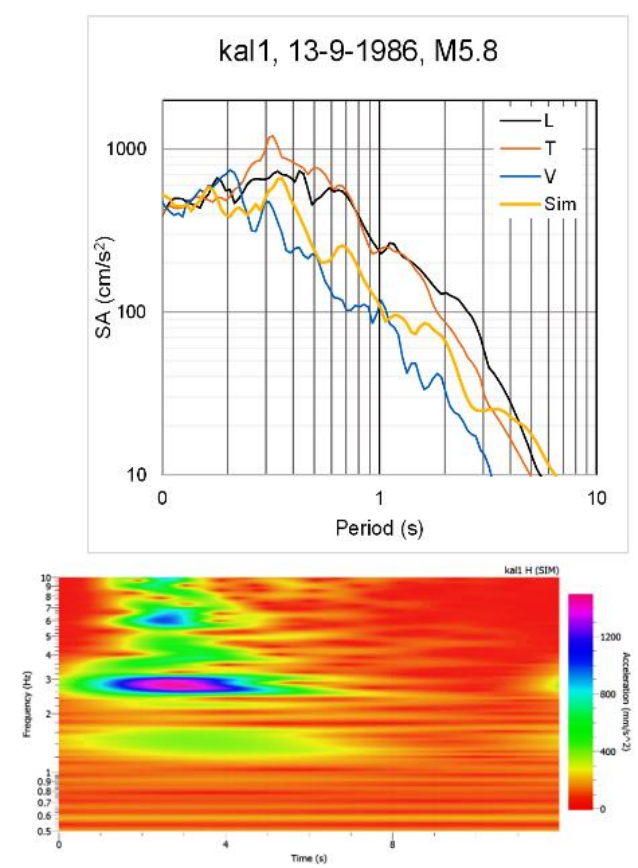

Figure 2 - (A) Observed (L, T, V) and synthetic (Sim) response spectra (h=5\%); (B) Synthetic spectrograms where the color scale represents ground acceleration ranging from red (low) to purple (high).

The damage scenarios are then elaborated by: a) attribution of the interpolated synthetic intensity to each sampled building block, b) computation of the mean damage grade per building and the average mean damage grade per block, c) distribution of the probabilities of occurrence of the mean damage grade, d) definition of the most probable damage grade per block. Figure 4 Right and Figure 5 illustrate the resulted damage distribution for scenarios A, B and D. Scenario D leads to more favorable results, whereas the extreme scenario B depicts the highest expected damages. By juxtaposition with the hazard map of Figure 4 Left, it is confirmed that the risk increment in the aforementioned areas is likely due to site conditions.

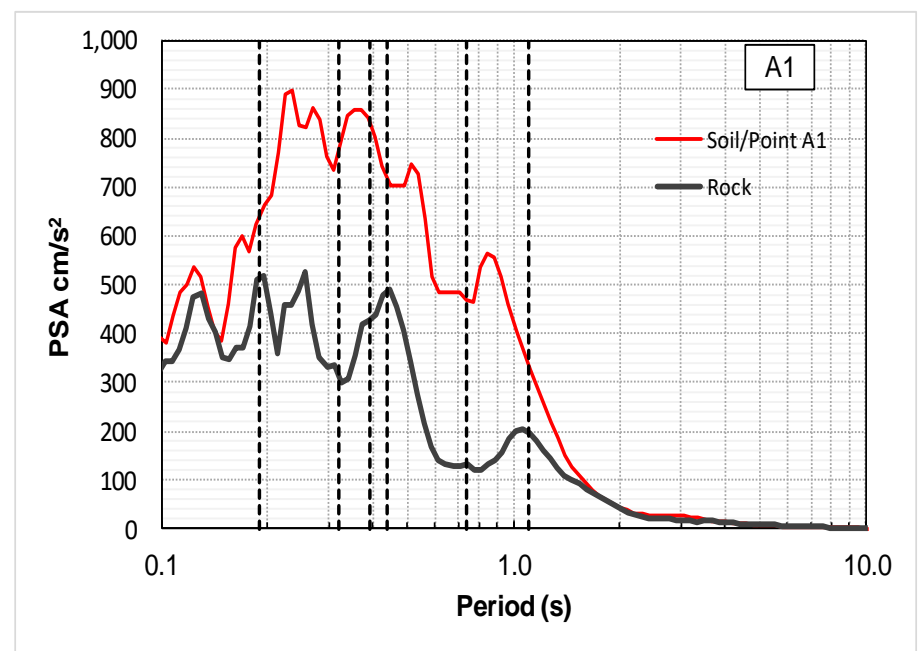

Figure 3 - Example of response spectra regarding soil (red) and bedrock (black) conditions. The dashed vertical lines indicate the eigenvibration period of the main structural categories. 

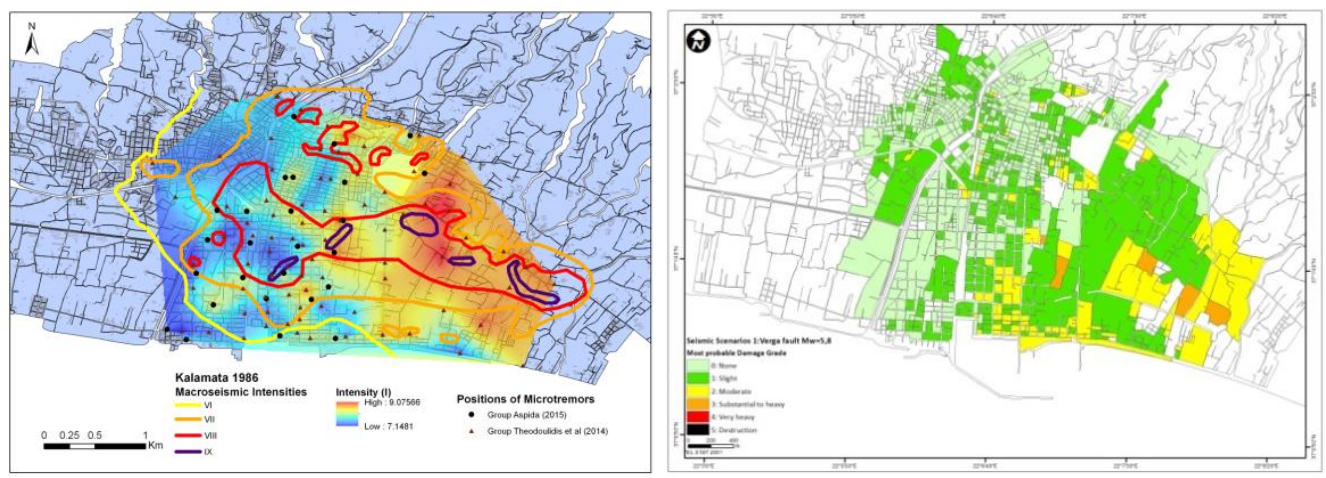

Figure 4 - Left: Hazard map showing the distribution of synthetic intensities determined for

the scenario 1986 earthquake. Superimposed are the isoseismal map of the 1986 event

(Leventakis et al., 1992) and the positions of microtremors measurements (solid circles and triangles). Right: Damage distribution for scenario A (1986 earthquake).
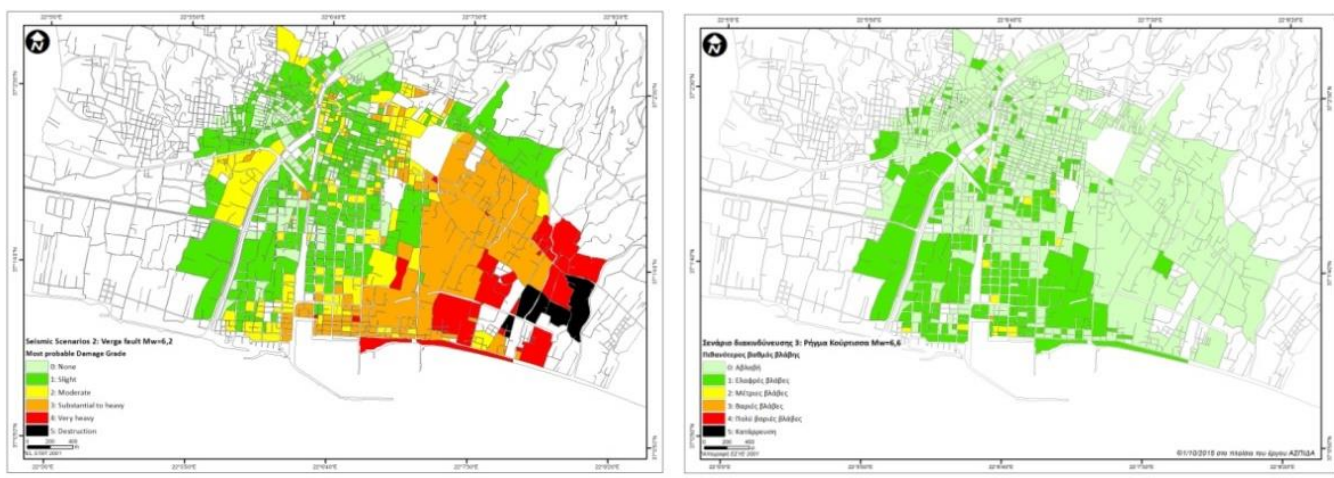

Figure 5 - Damage characterization per building block. Left: Scenario B. Right: Scenario D. Damage is color coded as: light green-no damage, dark green-slight damage, yellowmoderate damage, orange-heavy damage, red: very heavy damage, black: collapse).
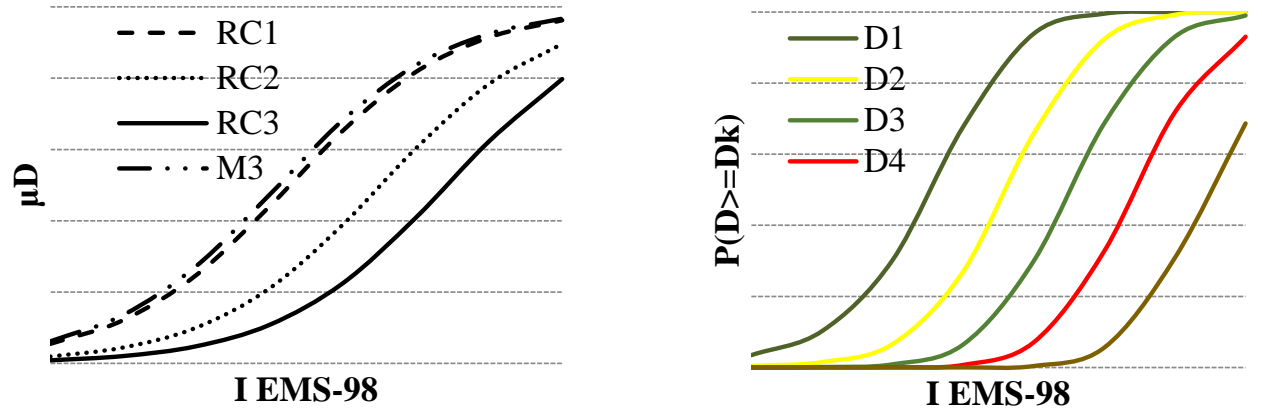

Figure 6 - Left: Vulnerability curves of main structural typologies; Right: Fragility curves for RC2 typology (right); both for the nearest MCE.

An indispensable outcome of an extensive risk study is to develop vulnerability and fragility curves for each structural type. Vulnerability curves, illustrating the function between seismic intensity and the potential damage grade, can be of use for rapid and direct estimation of the expected damage grade of buildings of certain structural typology at any seismic intensity. Fragility curves, which 
depict the probability of exceedance of each damage grade, with respect to the seismic intensity, are used to estimate loss models, in terms of financial and human consequences. Hereby, vulnerability and fragility functions were determined by combining detailed ground motion and structural characteristics (Figure 6) and hence they are suggested to be considered optimal assessment modules for the city of Kalamata.

\section{Discussion and conclusions}

The present work integrates seismic vulnerability and hazard assessment towards developing seismic risk models for the city of Kalamata at a building block scale. A massive dataset comprising structural, geological, geotechnical and seismological information was processed. Macroseismic vulnerability was estimated using the EMS-98 which has been proven to be suitable for the seismic characterization of European buildings. Seismic hazard was assessed by a deterministic approach, using the active tectonic setting, attenuation parameters resolved for Greek earthquakes and site specific amplification functions derived by dense ambient noise recordings applying the popular Nakamura technique. As far as the applied methodology is concerned, it is considered to be a probabilistic approach as soon as a set of uncertainties is introduced in its various stages regarding both the ground shaking and the macroseismic vulnerability input.

7960 buildings were studied, mainly of residential and commercial use, many of them being built after the 1986 earthquake which destroyed a large portion of masonry buildings, hence substituted by new constructions obeying more modern seismic provisions. Four damage scenarios have been developed by stochastic simulation of the strong ground motion at numerous positions in Kalamata considering the known most hazardous faults for the target site. The overall damage distribution is summarized in Table 1, in comparison with the effects of the 1986 earthquake.

Table 1 - The average damage grade estimates for each scenario regarding residential and commercial buildings in Kalamata. A-D: the four implemented scenarios (see text), MCE: Maximum Credible Earthquake.

\begin{tabular}{|c|c|c|c|c|c|c|c|}
\hline \multirow{2}{*}{ Case } & \multirow{2}{*}{ Fault/Mw } & \multicolumn{7}{|c|}{$\boldsymbol{\mu}_{\mathbf{D}}$ (\% of 7960 buildings) } \\
\cline { 3 - 9 } & & $\mathbf{0}$ & $\mathbf{1}$ & $\mathbf{2}$ & $\mathbf{3}$ & 4 & 5 \\
\hline $13 / 9 / 1986$ & Verga/5.8 & \multicolumn{2}{|c|}{28} & 36 & 16 & 20 & - \\
\hline A & Verga/5.8 & 54.3 & 24.4 & 16.1 & 4.3 & 0.8 & 0.0 \\
\hline B (MCE) & Verga/6.2 & 27.7 & 27.0 & 17.7 & 17.0 & 8.1 & 2.6 \\
\hline C & Kourtissa/6.6 & 61.7 & 22.6 & 13.4 & 2.1 & 0.1 & 0.0 \\
\hline D & Pidima/6.0 & 67.9 & 26.7 & 4.9 & 0.5 & 0.0 & 0.0 \\
\hline
\end{tabular}

As it can be seen in Table 1, scenario A (simulation of the 1986 earthquake) certainly leads to a much lower damage with respect to the one caused by the real earthquake (OASP, 1996), simply because a large part of the town was rebuilt after the 1986 earthquake, in accordance to modern seismic codes and many of the most vulnerable structures have already been demolished or abandoned. On the contrary, the nearest MCE for Kalamata with Mw6.2 on the same fault leads to a higher level of damage. Scenarios C and D regarding Kourtissa and Pidima faults, respectively, lead to more favourable consequences.

A novelty of the current work is the linkage of vulnerability/fragility with local site conditions by employing response spectra ratios (RSR) between the site and the underlain bedrock, which were further applied to each building in terms of modification scores, representing the soil-structure interaction effect. In this regard, new vulnerability and fragility curves were determined, properly adapted for Kalamata. As soon as these functions are proven site-sensitive it is suggested that they should be adapted to the site's specific characteristics when studying seismic risk. 
Our method is fast, cost effective and despite the unavoidable data uncertainties, it is proposed to be considered in the framework of a National roadmap towards predicting urban earthquake effects. Options for its further improvement are outlined as following:

- Rearrangement of vulnerability indexes considering updated damage data.

- Rearrangement of vulnerability and seismic hazard weighting input after sensitivity analysis.

- Extension to loss assessment regarding casualties and socioeconomic consequences.

- Registration of the buildings characteristics by experts.

- Application of simplified mechanical methods for the vulnerability assessment (HAZUS, 1999; RISK-UE-LM2: Milutinovic and Triandafiloski, 2003) and/or further evaluations by analytical methods of buildings of high importance.

- A major restriction towards the implementation of the approach in a National level is the lack of a database including geospatial data per area. Such data, definitely existing into oldanalogue and recent-digital archives are suggested to be centralized and disseminated to the scientific and professional community.

\section{Acknowledgements}

This work has been implemented under the project KRIPIS-ASPIS "Infrastructure Upgrade for Seismic Protection of the Country and Strengthen Service Excellence through Action". We would like to thank N. Theodulidis, G. Papadopoulos, E. Vintzilaiou, D. Vamvatsikos, E. Lekkas, M. Panoutsopoulou, I. Vasileiou, S. Mpirmpilopoulos for their help that greatly contributed in the current research.

\section{References}

ASPIDA, 2015. Infrastructure Upgrade for Seismic Protection of the Country and Strengthen Service Excellence through Action, project MIS-448326, implemented under the Action, Development Proposals for Research Bodies-ASPIS-KRIPIS (in greek).

Beresnev, I.A. and Atkinson, G.M., 1997. Modeling finite-fault radiation from the $\omega^{2}$ spectrum, Bull. Seismol. Soc. Am., 87, 67-84.

Boore, D.M., 2003. Prediction of ground motion using the stochastic method, Pure Appl. Geophys., 160, 635-676.

Brune, J.N., 1970. Tectonic stress and spectra of seismic shear waves from earthquakes, J Geophys Res., 75, 4997-5009.

Calvi, G.M., Pinho, R., Magenes, G., Bommer, J., Restrepo-Velez, L.F. and Crowley, H., 2006. Development of seismic vulnerability assessment methodologies over the past 30 years, Indian. Soc. J. Earthq. Technol., 43(3), 75-104.

EPANTYK, 2009. Development of GIS software for the Representation of the Structural wealth of the municipalities of the country and of its Structural Vulnerability in buildings block level, YP.ES.A and H.D., KEDKE \&TEE 39 pp. (in greek).

Giovinazzi, S. and Lagomarsino, S., 2004. A macroseismic method for the vulnerability assessment of buildings. Paper $\mathrm{N}^{\circ}$ 896, Proceedings of the 13th World Conference on Earthquake Engineering, Vancouver.

Grünthal, G., ed., 1998. Cahiers du Centre Européen de Géodynamique et de Séismologie: Vol. 15, European Macroseismic Scale 1998, Europ. Center for Geodyn. and Seism., Luxembourg.

HAZUS, 1999. Earthquake Loss Estimation Methodology - Technical and User Manuals, Federal Emergency Management Agency, Washington D.C. 
Kassaras, I., Kalantoni, D., Benetatos, C., Kaviris, G., Michalaki, K., Sakellariou, N. and Makropoulos, K., 2015. Seismic damage scenarios in Lefkas old town (W. Greece), Bull. Earthquake Engineering., doi: 10.1007/s10518-015-9789-z.

Kassaras, I., Kalantoni, D., Kouskouna, V., Pomonis, A., Michalaki, K., Stoumpos, P., Mourloukos, S., Birmpilopoulos, S. and Makropoulos, K., 2014. Correlation between damage distribution and soil characteristics deduced from ambient vibrations in the old town of Lefkada (W. Greece), 2ECEES, Istanbul, Paper No 251.

Lagomarsino, S. and Giovinazzi, S., 2006. Macroseismic and mechanical models for the vulnerability and damage assessment of current buildings, Bull. Earthquake Engineering, 4, 415-443.

Leventakis, G.A., Lekidis, V., Papaioannou, Ch., Zacharopoulos, S., Tsokas, G. and Kiratzi, A., 1992. Equal-Intensity contour map for the city of Kalamata due to September 1986 earthquake, Proc. 1st Hellenic Conf. of Earthquake Engin. and Engin. Seismology, 2, 321330 (in Greek).

Lyon-Caen, H., Armijo, R., Drakopoulos, J., Baskoutass, J., Delibassis, N., Gaulon, R., Kouskouna, V., Latousakis, J., Makropoulos, K., Papadimitriou, P., Panastasiou, D. and Pedotti, G., 1988. The 1986 Kalemate (South Peloponnesus) Earthquake.

Makropoulos, K, Kaviris, G. and Kouskouna, V., 2012. An updated and extended earthquake catalogue for Greece and adjacent areas since 1900, Nat. Hazards Earth Syst. Sci., 12, 14251430.

Margaris, B.N. and Boore, D.M., 1998. Determination of $\Delta \sigma$ and $\kappa_{0}$ from Response Spectra of Large Earthquakes in Greece, BSSA, 88,170-182.

Milutinovic, Z. and Trendafiloski, G., RISK-UE, 2003. An advanced approach to earthquake risk scenarios with applications to different European towns, ReportWP4: vulnerability of current buildings, Risk-UE, European Commission, Brussels.

Nakamura, Y., 1989. A method for dynamic characteristics estimation of subsurface using microtremor on the ground surface, RTRI, 30, 1, 25-33.

OASP, 1996. Systematic Presentation of Results and Conclusions of Microzonation Study Research Programs of Kalamata, Earthquake Planning and Protection (in greek).

Panou, A, Theodoulidis, N, Hatzidimitriou, P, Stylianidis, K. and Papazachos, C., 2005. "Ambient noise horizontal-to-vertical spectral ratio in site effects estimation and correlation with seismic damage distribution in urban environment: The case of the city of Thessaloniki (Northern Greece)", Soil Dyn. and Earth. Eng., 25, 261-274.

Papazachos, B. and Papazachou, C., 2003. The Earthquakes of Greece, Third Ed., Ziti Public., Thessaloniki, $286 \mathrm{pp}$.

Roumelioti, Z, Kiratzi, A. and Theodoulidis, N, 2004. Stochastic Strong Ground-Motion Simulation of the 7 September 1999 Athens (Greece) Earthquake, BSSA, 94, 3, 1036-105.

SESAME, 2005. Guidelines for the implementation of the H/V spectral ratio technique on ambient vibrations-measurements, processing and interpretations, SESAME European research project EVG1-CT-2000-00026, deliverable D23.12.

Theodulidis, N., Cultrera, G., Tento, A., Faeh, D., Atakan, K., Bard, P-Y., Panou, A. and the SESAME Team, 2004. Empirical evaluation of the Horizontal to vertical spectral ratio technique: Results from the SESAME Project, Proceedings of the 13th World Conference on Earthquake Engineering, Paper No.2323, 1-6 August 2004, Vancouver, Canada.

Tselentis, G. and Danciu, L, 2008. Empirical Relationships between Modified Mercalli Intensity and Engineering Ground-Motion Parameters in Greece, BSSA, 98, 4, 1863-1875.

Wells, D.L. and Coppersmith, K.J., 1994. New Empirical Relationships among Magnitude, Rupture Length, Rupture Width, Rupture Area, and Surface Displacement.

Wyss, M. and Rosset, P., 2013. Mapping seismic risk: the current crisis, Nat. Hazards, doi: 10.1007/s11069-012-0256-8. 